\title{
Beyond cell replacement: unresolved roles of NG2-expressing progenitors
}

\section{Enrica Boda* and Annalisa Buffo}

Department of Neuroscience Rita Levi-Montalcini, Neuroscience Institute Cavalieri Ottolenghi, University of Turin, Turin, Italy

\section{Edited by:}

Luca Bonfanti, University of Turin, Italy

Reviewed by:

Hans Georg Kuhn, University of Gothenburg, Sweden

Akiko Nishiyama, University of Connecticut, USA

\section{${ }^{*}$ Correspondence:}

Enrica Boda, Department of Neuroscience Rita Levi-Montalcini, Neuroscience Institute Cavalieri Ottolenghi, University of Turin, Regione Gonzole 10, Orbassano 10043 (Turin), Italy

e-mail:enrica.boda@unito.it
NG2-expressing parenchymal precursors (NG2+p) serve as primary source of myelinating oligodendrocytes in both the developing and adult Central Nervous System (CNS). However, their abundance, limited differentiation potential at adult stages along with stereotypic reaction to injury independent of the extent of myelin loss suggest that NG2+p exert functions additional to myelin production. In support of this view, NG2+p express a complex battery of molecules known to exert neuromodulatory and neuroprotective functions. Further, they establish intimate physical associations with the other CNS cell types, receive functional synaptic contacts and possess ion channels apt to constantly sense the electrical activity of surrounding neurons. These latter features could endow $\mathrm{NG} 2+\mathrm{p}$ with the capability to affect neuronal functions with potential homeostatic outcomes. Here we summarize and discuss current evidence favoring the view that $\mathrm{NG} 2+p$ can participate in circuit formation, modulate neuronal activity and survival in the healthy and injured CNS, and propose perspectives for studies that may complete our understanding of $\mathrm{NG} 2+\mathrm{p}$ roles in physiology and pathology.

Keywords: buffering, depolarization, myelin, neuroprotection, neuromodulation

\section{INTRODUCTION}

During Central Nervous System (CNS) ontogenesis, myelinating oligodendrocytes originate from highly ramified neural precursors expressing the platelet-derived growth factor alpha receptor (PDGFRa) and the NG2 chondroitin sulfate proteoglycan (Zhu et al., 2008a,b). These precursors persist in the adult CNS parenchyma, where constitute the main proliferative cell type and make up about $5 \%$ of all CNS cells (Dawson et al., 2003). At adult stages, they can engage into maturation to sustain a certain degree of basal myelin turnover and plasticity (Wang and Young, 2013; Young et al., 2013) and are rapidly mobilized to replace oligodendrocytes in demyelination (Redwine and Armstrong, 1998; Zawadzka et al., 2010). Herein we will refer to these cells as NG2expressing precursors (NG2+p), although NG2 is also expressed by pericytes of the vasculature (Stallcup, 2002) and reported in astrocyte subsets (Matthias et al., 2003).

Currently, the only unequivocally established functions of $\mathrm{NG} 2+\mathrm{p}$ are to regenerate themselves and produce oligodendrocytes in the healthy, diseased and aged CNS (Zhu et al., 2008a,b; Kang et al., 2010; Tripathi et al., 2010; Young et al., 2013). However, the persistence of a large pool of quiescent (i.e., neither engaged in proliferation nor maturation) $\mathrm{NG} 2+\mathrm{p}$ with limited differentiation potential at adult ages has suggested that these cells do not only represent a transitional stage along the oligodendroglial lineage, but rather a novel type of glia endowed with specific properties and functions (Nishiyama et al., 2002). Consistently, NG2+p appear uniformly distributed in the gray and white matter and provide a stereotypic reaction to injury independently of the extent of myelin loss, suggesting that they may play roles additional to myelin production. Along this line, it has been proposed that $\mathrm{NG} 2+\mathrm{p}$ may be multipotent progenitors endowed with the ability to generate astrocytes and neurons in defined conditions. However, to date consensus is established only for the generation of astrocyte subsets at perinatal stages (Rivers et al., 2008; Zhu et al., 2008a,b; Huang et al., 2014). Here we will overview and discuss features potentially related to surveillance, neuromodulation and neuroprotection that still render NG2+p very enigmatic and prompt further investigations on this type of glia.

\section{NG2+p ANATOMICAL RELATIONSHIP WITH CNS CELLS AND PARACRINE INTERACTIONS}

In both human and rodent CNS, NG2 $+\mathrm{p}$ appear distributed rather homogeneously in gray and white matter areas, with no correlation between their density and that of myelin (Butt et al., 2005; Staugaitis and Trapp, 2009). NG2+p processes extend tridimensionally to cover non-overlapping fields that are likely maintained by homotypic repulsive mechanisms (Hughes et al., 2013). Accordingly, in the intact tissue contacts among $\mathrm{NG} 2+\mathrm{p}$ processes are rarely observed (Hughes et al., 2013) and, despite some NG2+p express connexin 32 (Melanson-Drapeau et al., 2003), cells are never coupled via gap-junctions (Wallraff et al., 2004; Butt et al., 2005). Thus, at variance with astrocytes, NG2+p do not function as a syncythium, but are rather individual functional units. However, they partly couple to mature oligodendrocytes, indicating some privileged communication with other elements in the lineage (Maglione et al., 2010).

Confocal and electron microscopy analyses showed that $\mathrm{NG} 2+\mathrm{p}$ establish intimate anatomical and functional contacts with other CNS cells. NG2 $+p$ processes form multiple contacts with dendrites and axons, and NG2+p arborizations intertwine amongst and can encapsulate neuronal somata (Wigley and Butt, 
2009; see also Figures 1A, $\mathbf{A}^{\prime}$ ) in ways suggestive of their participation in perineuronal nets (Butt et al., 2005). Electron microscopy further revealed that $\mathrm{NG} 2+\mathrm{p}$ processes make contacts with the axonal membrane at the paranodes and nodes of Ranvier (Butt et al., 1999), and interdigitate between pre- and post-synaptic neuronal elements (Ong and Levine, 1999). Contacts with axons include also functional neuron-to-NG2+p synapses (see below). Of note, tight NG2+p-neuron associations exist also in the CNS of adult non-mammalian vertebrates (i.e., zebrafish; März et al., 2010), in line with a fundamental mechanism of communication conserved through species.

Intimate physical interactions also occur with astrocytes. Both cell types often contact the same neurons/axonal terminals (Wigley and Butt, 2009) but NG2+p never ensheat neuronal synapses as astrocytes do. Interestingly, areas of immediate apposition in $\mathrm{NG} 2+\mathrm{p}$ and astrocyte processes are sites of communication, where astrocyte-derived signals induce $\mathrm{Ca}^{2+}$ transients in NG2+p (Hamilton et al., 2010). At those sites synaptophysinpositive clusters indicative of secretory vesicle accumulation were observed in $\mathrm{NG} 2+\mathrm{p}$, pointing to potential secretory spots (Wigley and Butt, 2009). NG2+p also make direct contacts with microglia (Nishiyama et al., 1997), pericytes and myelin (Butt et al., 2005). Hence, NG2+p connect to distinct cell types and functionallyrelevant cellular domains, suggesting that they may actively sense and integrate information from diverse sources. An additional level of integration occurs through paracrine signals produced by neighboring cells including neurons, astrocytes and microglia, and influences $\mathrm{NG} 2+\mathrm{p}$ during developmental myelination and in pathology (see Clemente et al., 2013 for review). Is the output of this integration (see below) limited to the regulation of $\mathrm{NG} 2+\mathrm{p}$ differentiation or survival? It is surprising that $\mathrm{NG} 2+\mathrm{p}$ are generally considered only as a sink and not as a source of signals. Hence, if and how $\mathrm{NG} 2+\mathrm{p}$ affect surrounding cells remains essentially unknown.

\section{PRIVILEGED CONTACTS WITH NEURONS}

What makes $\mathrm{NG} 2+\mathrm{p}$ unique amongst other glial cells is their connection with neurons through synapses that sense neuronal activity at the quantal level with high temporal and spatial resolution. These contacts emerge in parallel with neuronal synaptogenesis and appear ubiquitary, being present in all regions examined so far (cerebellar and cerebral cortex, Lin et al., 2005; Kukley et al., 2008; Ge et al., 2009; Tanaka et al., 2009; Vélez-Fort et al., 2010; hippocampus, Lin and Bergles, 2004; Mangin et al., 2008; brain stem, Müller et al., 2009; white matter tracts, Kukley et al., 2007; Ziskin et al., 2007; Káradóttir et al., 2008; De Biase et al., 2010; Etxeberria et al., 2010). Synapses include glutamatergic and Gamma-Aminobutyric Acid (GABA)-ergic inputs, and both produce depolarizations. Full functionality of these contacts in vivo is attested by recordings of evoked, spontaneous, and miniature currents both in physiology and during remyelination (Etxeberria et al., 2010; Vélez-Fort et al., 2010). Glutamatergic contacts are lost as NG2+p progress in differentiation (De Biase et al., 2010; Kukley et al., 2010), in line with a role in the regulation of the cell cycle or of functions specific of the progenitor stage. Notably, glutamatergic inputs increase in frequency and amplitude in $\mathrm{NG} 2+\mathrm{p}$ cells during CNS maturation (Mangin et al., 2008), whereas in the cerebral cortex GABAergic signaling shifts from activation of synaptic receptors to indirect activation of extrasynaptic channels through spillover (Vélez-Fort et al., 2010; Balia et al., 2013; Passlick et al., 2013).

Glutamate- and GABA-induced depolarizations in $\mathrm{NG} 2+\mathrm{p}$ are overall modest in amplitude with the notable exception of cerebellar climbing fiber inputs that induce relevant potential variations (Lin et al., 2005). Thus, to affect the cell physiology, a number of convergent inputs from diverse synapses likely require be integrated. Transduction of synaptic signal may also rely on calcium-mediated mechanisms such as calcium entry though permeable $\alpha$-amino-3-hydroxy-5-methyl-4-isoxazolepropionic acid
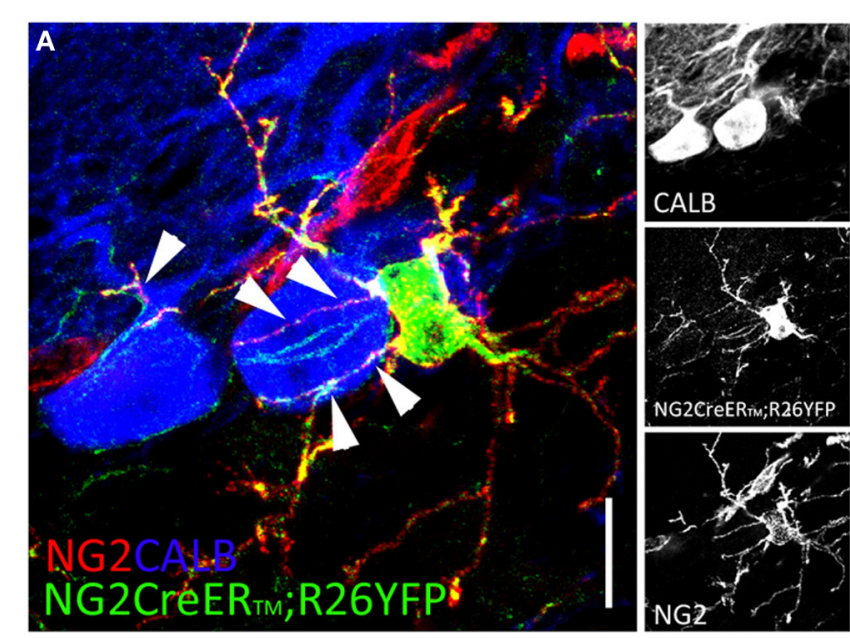

FIGURE 1 |NG2+p distribution in the adult cerebellum. (A, $\left.\mathbf{A}^{\prime}\right)$ Two weeks after tamoxifen induction, multiprocessed cells identified by NG2 (red), and YFP (green) expression appear closely associated to calbindin+ (blue) Purkinje cells in adult NG2CreER ${ }^{\mathrm{TM}}$; R26YFP mouse
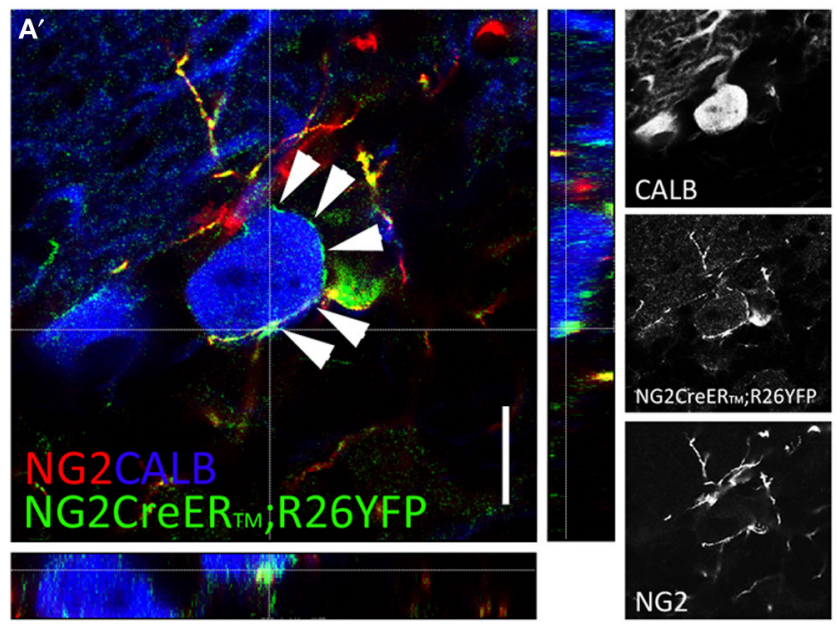

cerebellum. NG2 $+\mathrm{p}$ arborizations envelop Purkinje cell somata and dendrites [arrowheads in $\left(\mathbf{A}, \mathbf{A}^{\prime}\right)$ ]. (A) Confocal stack comprising 20 optical section $1 \mathrm{~mm}$ thick. (A') Single confocal plane. Scale bars: $10 \mu \mathrm{m}$. 
(AMPA) or N-methyl-D-aspartate (NMDA) receptors, and activation of voltage dependent conductances that provide signal amplification and can trigger calcium transients from intracellular stores. Notably, in the hippocampus neuron-to-NG2+p synapses undergo activity-dependent modifications analogous to long term potentiation (LTP) at excitatory synapses (Ge et al., 2006), showing that these contacts possess the machinery to sustain plastic changes. Moreover, glutamate or GABA evoked signals can be integrated intracellularly with responses to other mediators such as adenosine triphosphate (ATP), which, upon release by both axons and astrocytes, triggers calcium currents through P2Y and P2X receptors (Hamilton et al., 2010). Yet, depolarizations and calcium transients are mostly described as very local events that take place at the cell processes, where synapses are mostly found, and could therefore influence spatially restricted functions such as local protein synthesis, motility, or secretion (see also above, Kirby et al., 2006; Tanaka et al., 2009; Haberlandt et al., 2011; Wake et al., 2011; Hughes et al., 2013).

What is the functional significance of neuronal inputs? Since $\mathrm{NG} 2+\mathrm{p}$ do not appear able to transmit electrical signals to other cells, information derived from neuronal activity is likely to instruct functions specific to these progenitors. Several reports showed that neurotransmitters can affect proliferation and migration of NG2+p in vitro (Luyt et al., 2007; Gallo et al., 2008; Tong et al., 2009). Other studies related alterations in circuit activities at adult ages (including motor activity, sleep-wake cycles, experimental spreading depression, or enriched environment) to modulation of $\mathrm{NG} 2+$ p proliferation and maturation (Ehninger et al., 2011; Simon et al., 2011; Tamura et al., 2012; Bellesi et al., 2013). However, these findings, which appeared somewhat contradictory, only established a rather aspecific link between neuronal activity and $\mathrm{NG} 2+\mathrm{p}$ behaviors. In a recent report Mangin et al. (2012) addressed this issue more directly and found that sensory stimuli from the whisker pad regulate $\mathrm{NG} 2+\mathrm{p}$ number and distribution in the neonatal barrel cortex by negatively affecting cell proliferation. These data are in keeping with an inhibitory role of glutamatergic inputs on NG2 cell amplification and suggest that different inputs levels would result in proliferation-mediated accumulation of $\mathrm{NG} 2+\mathrm{p}$ at sites of relatively low electric activity. Such accumulations could then specifically predispose cells to start myelination (Mangin et al., 2012), as the achievement of a critical density is one of the key factors for myelin formation (Rosenberg et al., 2008). Electrical activity itself could likely further support the progression of postmitotic progenitors along the lineage, as it has long been known to be a myelination promoter (Demerens et al., 1996; Stevens et al., 2002; Lundgaard et al., 2013). Thus, the response of NG2+p to neuronal activity appears crucial to regulate their number and engagement in myelination during development, thereby contributing to structure the CNS architecture. Similarly, it could underlie myelin refinements related to learning and memory during adulthood. Yet, how these findings apply to the adult CNS and whether the large abundance of NG2+p present at adult stages is exclusively required to sustain the low grade of myelin turnover so far detected and/or experience-related circuit modulations remain to be assessed. Indeed, the occurrence of myelin remodeling appears rather low in the adult CNS (Zatorre et al., 2012; Young et al.,
2013) and at least in the gray matter the overall rate of NG2+p proliferation does not differ in myelin rich vs. myelin low territories (our unpublished observations) thus showing to be unrelated to myelin turnover. Further, exploiting the high metabolic charge of electric activity solely to tonically limit NG2+p proliferation appears poorly efficient, particularly in light of data showing that homotypic density cues play a major role in the regulation of NG2+p proliferation at adult stages (Hughes et al., 2013). Moreover, the observation that an important part of NG2+ clones in the gray matter do not generate oligodendrocytes in the adult brain (Levison et al., 1999; Zhu et al., 2011) raises the question as to whether $\mathrm{NG} 2+\mathrm{p}$ responses to neuronal inputs may include functions other than proliferation control or lineage progression.

\section{NG2+p FUNCTIONS BEYOND MYELINATION?}

Recently discovered features of $\mathrm{NG} 2+\mathrm{p}$ point to additional neuromodulatory and neuroprotective actions of this population. Some of these traits appear specifically related to the particular capability of $\mathrm{NG} 2+\mathrm{p}$ to sense and respond to electrical activity. Others, including the expression of growth factors, morphogens, cytokines, chemokines, and extracellular matrix (ECM) components, can instead be viewed as properties inherent in the progenitor nature of these cells, and may well correspond to the reparative bystander actions that germinal neural progenitors exert either in situ or upon grafting in the lesioned CNS (Martino and Pluchino, 2006; Butti et al., 2012).

Of note, evidence that $\mathrm{NG} 2+\mathrm{p}$ express synaptophysin suggests they may be capable of regulated secretion and bidirectional communication with astrocytes and neurons (Wigley and Butt, 2009). Of relevance in this context, Maldonado et al. (2013) have shown that during postnatal maturation $\mathrm{NG} 2+\mathrm{p}$ become progressively more sensitive to extracellular potassium increases generated by action potentials thanks to upregulation of Kir4.1 inward rectifying potassium channels. These channels mediate inward currents in conditions of high potassium and constitute one of the mechanisms through which astrocytes perform potassium buffering in the extracellular space, which is a requisite for correct neuronal transmission and excitability. In adult $\mathrm{NG} 2+\mathrm{p}$, besides contributing to set the resting membrane potential, these channels may help with removing high extracellular potassium and regulating neuronal functions at sites of close appositions to neurons (see above) (Maldonado et al., 2013). This could be a NG2+p specific mechanisms occurring upon single neuron firing, which may remain undetected by astrocytes (Maldonado et al., 2013).

$\mathrm{NG} 2+\mathrm{p}$ are also known to express several ECM components such as tenascins, versicans, neurocans, phosphacan, hyaluronan and even hyaluronan, and proteoglycan link protein 1 (HPLN1), which act as synaptic stabilizers by anchoring the neurotransmitter receptors to the cytoskeleton and contribute to perineuronal nets formation (Butt et al., 2005; Sim et al., 2009; see also Sim and Goldman, 2013). Given the intimate association of NG2 processes with neuronal pre- and post-synaptic elements and that neighboring pairs of $\mathrm{NG} 2+\mathrm{p}$ and neurons receive synaptic contacts from the same neurons (Bergles et al., 2000; Lin et al., 2005; Mangin et al., 2008), it can be hypothesized that NG2+p monitor neuron-neuron synapses and, depending on synchronization levels, act on synaptic stabilization and network organization 
by modifying the perisynaptic microenvironment. Interestingly, human NG2+p also show enriched levels of thrombospondin 2 (Sim et al., 2006), which is known as a synaptogenic cue released by immature astrocytes (Christopherson et al., 2005). Seminal studies demonstrating the role of astroglia in synaptic strengthening and formation also attributed a relevant effect to cells of the oligodendroglial lineage (Pfrieger and Barres, 1997). However, these data should be re-considered in light of the need to clarify the purity of cells and actual maturation stages. Yet, in line with an early function in circuit formation, acute deletion of cycling oligodendroglial cells have been reported to induce rapid changes in the expression of molecules involved in synaptic plasticity, axon growth and guidance in the cerebellum at birth, indicative of fast activation of remodeling mechanisms (Doretto et al., 2011). Previous experiments at later developmental stages have shown that myelin formation shapes cerebellar connections by removing exuberant collateral branches of Purkinje neurons (Gianola et al., 2003). These results suggest that cycling NG2+p participate in shaping cerebellar circuits well before myelination starts.

Neuroprotective mechanisms have been also proposed to be activated in NG2+ cells upon lesion. NG2+p provide a stereotyped response to injury, unrelated to the extent of myelin loss and of their own damage, which includes a precocious activation of proliferation and hypertrophy and is mediated by inflammatory and danger related signals (Levine et al., 2001; Nielsen et al., 2006). The sensitivity of these cells to changes in nerve conduction and neurotransmission could also influence NG2+p reactivity. Tanaka et al. (2009) reported that GABA-receptor mediated excitation in $\mathrm{NG} 2+\mathrm{p}$ after ischemic stroke increases brain-derived neurotrophic factor (BDNF) production, which was instead blocked by inhibition of GABA-mediated depolarization. The authors further hypothesize that $\mathrm{NG} 2+\mathrm{p}$-derived BDNF participate in post-stroke reparative mechanisms. Given the well-known actions of BDNF in promoting synaptic transmission, plasticity, and growth (Lu et al., 2013), these speculations could be extended to include modulatory actions of neuronal functions in physiological conditions. Along this line, reactive $\mathrm{NG} 2+\mathrm{p}$ responding to depolarizing waves induced by experimental cortical spreading depression were reported to upregulate the peptide galanin and proposed to release it to receptor positive cortical neurons with the purpose of limiting excitotoxic damage (Shen et al., 2003). In a recent in vitro study Sypecka and Sarnowska (2013) provided first evidence in support of a pro-survival action of $\mathrm{NG} 2+\mathrm{p}$ on the injured nervous tissue. In co-cultures of primary $\mathrm{NG} 2+\mathrm{p}$ with organotypic hippocampal slices subjected to oxygen-glucose deprivation, the authors observed a significant rescue of neuronal viability and identify BDNF, interleukin-10, stem cell factor (SCF) as agents through which $\mathrm{NG} 2+$ p perform immunomodulatory and protective functions in their experimental setting. Accordingly, NG2+p derived from human embryonic stem cells express transforming growth factor (TGF) $\beta 2$, a potent inhibitor of inflammation, midkine, and activine A, two neurosupportive factors that are highly upregulated early after injury (Munz et al., 2001; Zhang et al., 2006; Yoshida et al., 2014). NG2+p cells could therefore share the capability of mature oligodendrocytes to produce neurotrophic factors, influence adjacent cells (Wilkins et al., 2001;
Dai et al., 2003) and especially neurons in physiology and conditions of cell stress (Lee et al., 2012; Frühbeis et al., 2013). Further, in amyloidosis models it has been reported that NG2+p internalize and degrade $\beta$-amyloid1-42 by autophagy (Li et al., 2013). Thus, together with astrocytes and microglia, NG2+ glia could also participate in the clearance of amyloid as part of their reactive response (Boda et al., 2011; Behrendt et al., 2013).

The potential reparative and supportive actions may be specifically triggered by $\mathrm{NG} 2+\mathrm{p}$ reactivity or be already present in resting conditions and become amplified as a consequence of the NG2+p widespread cytogenic response to damage. However, these considerations remain speculative, because a detailed and comprehensive examination of $\mathrm{NG} 2+\mathrm{p}$ changes upon lesion is not available. What is instead better assessed is the contribution of $\mathrm{NG} 2+\mathrm{p}$ to scar formation and the inhibitory role of chondroitin sulfate proteoglycans-including NG2 - in axon remodeling and regrowth of transected axons (Galtrey and Fawcett, 2007), recently accompanied by evidence for conduction blockade exerted by NG2 at nodes of Ranvier after spinal cord transection (Petrosyan et al., 2013). While these inhibitory effects are mostly seen as detrimental for circuit rewiring, they could be part of a mechanism necessary to contain excitoxicity and damage extension, as formerly shown for astrocytes (Buffo et al., 2010). Further, actions restricting plasticity may be compensated by an increment in the availability of prosurvival factors determined by both $\mathrm{NG} 2+\mathrm{p}$ reactivity and proliferation.

\section{CONCLUDING REMARKS}

Intense research over the last decades has revealed key insights into $\mathrm{NG} 2+\mathrm{p}$ physiopathology related to myelinogenesis. Nevertheless, fundamental aspects of $\mathrm{NG} 2+\mathrm{p}$ biology remain undetermined. For example, while NG2+p are known to respond to signals produced by neurons, astrocytes, and microglia, whether this communication is reciprocal and how it occurs is substantially neglected. NG2+p-derived signaling may include morphogenic, neuromodulatory, and neuroprotective factors whose elucidation may also have therapeutic implications for the implementation of the endogenous reparative potential of injured CNS. In vivo approaches aimed at selectively and timely ablating NG2+p in the CNS, together with the identification of active paracrine/juxtacrine factors produced by $\mathrm{NG} 2+\mathrm{p}$, will be highly instrumental to address these issues, especially to understand how much it is crucial to maintain such a high number of cells to sustain myelin turnover and plasticity in the adult CNS and whether any relevant alteration in neuronal functions occurs in the absence of $\mathrm{NG} 2+\mathrm{p}$ in the intact or injured CNS.

\section{ACKNOWLEDGMENTS}

The work of Enrica Boda and Annalisa Buffo is supported by the Italian Ministry for University and Research (MIUR, PRIN 20107MSMA4, Annalisa Buffo). Enrica Boda is supported by a postdoctoral fellowship of the Giuseppe Levi Foundation, Accademia Nazionale dei Lincei, Rome, Italy. We thank Elena Frola and Giulia Pregno for the courtesy of the pictures in Figure 1. 


\section{REFERENCES}

Balia, M., Vélez-Fort, M., Passlick, S., Schäfer, C., Audinat, E., Steinhäuser, C., et al. (2013). Postnatal down-regulation of the GABAA Receptor $\gamma 2$ subunit in neocortical NG2 cells accompanies synaptic-to-extrasynaptic switch in the GABAergic transmission mode. Cereb. Cortex. doi: 10.1093/cercor/ bht309. [Epub ahead of print].

Behrendt, G., Baer, K., Buffo, A., Curtis, M. A., Faull, R. L., Rees, M. I., et al. (2013). Dynamic changes in myelin aberrations and oligodendrocyte generation in chronic amyloidosis in mice and men. Glia 61, 273-286. doi: 10.1002/glia.22432

Bellesi, M., Pfister-Genskow, M., Maret, S., Keles, S., Tononi, G., and Cirelli, C. (2013). Effects of sleep and wake on oligodendrocytes and their precursors. J. Neurosci. 33, 14288-14300. doi: 10.1523/JNEUROSCI.5102-12.2013

Bergles, D. E., Roberts, J. D., Somogyi, P., and Jahr, C. E. (2000). Glutamatergic synapses on oligodendrocyte precursor cells in the hippocampus. Nature. 405, 187-191. doi: 10.1038/35012083

Boda, E., Viganò, F., Rosa, P., Fumagalli, M., Labat-Gest, V., Tempia, F., et al. (2011). The GPR17 receptor in NG2 expressing cells: focus on in vivo cell maturation and participation in acute trauma and chronic damage. Glia 59, 1958-1973. doi: 10.1002/glia.21237

Buffo, A., Rolando, C., and Ceruti, S. (2010). Astrocytes in the damaged brain: molecular and cellular insights into their reactive response and healing potential. Biochem. Pharmacol. 79, 77-89. doi: 10.1016/j.bcp.2009.09.014

Butt, A. M., Duncan, A., Hornby, M. F., Kirvell, S. L., Hunter, A., Levine, J. M., et al. (1999) Cells expressing the NG2 antigen contact nodes of Ranvier in adult CNS white matter. Glia 26, 84-91.

Butt, A. M., Hamilton, N., Hubbard, P., Pugh, M., and Ibrahim, M. (2005). Synantocytes: the fifth element. J. Anat. 207, 695-706. doi: 10.1111/j.14697580.2005.00458.x

Butti, E., Bacigaluppi, M., Rossi, S., Cambiaghi, M., Bari, M., Cebrian Silla, A., et al. (2012). Subventricular zone neural progenitors protect striatal neurons from glutamatergic excitotoxicity. Brain 135, 3320-3335. doi: 10.1093/brain/aws194

Christopherson, K. S., Ullian, E. M., Stokes, C. C., Mullowney, C. E., Hell, J. W., Agah, A., et al. (2005). Thrombospondins are astrocyte-secreted proteins that promote CNS synaptogenesis. Cell 120, 421-433. doi: 10.1016/j.cell.2004.12.020

Clemente, D., Ortega, M. C., Melero-Jerez, C., and de Castro, F. (2013). The effect of glia-glia interactions on oligodendrocyte precursor cell biology during development and in demyelinating diseases. Front. Cell. Neurosci. 7:268. doi: $10.3389 /$ fncel.2013.00268

Dai, X., Lercher, L. D., Clinton, P. M., Du, Y., Livingston, D. L., Vieira, C., et al. (2003). The trophic role of oligodendrocytes in the basal forebrain. J. Neurosci. 23, 5846-5853.

Dawson, M. R., Polito, A., Levine, J. M., and Reynolds, R. (2003). NG2-expressing glial progenitor cells: an abundant and widespread population of cycling cells in the adult rat CNS. Mol. Cell. Neurosci. 24, 476-488. doi: 10.1016/S10447431(03)00210-0

De Biase, L. M., Nishiyama, A., and Bergles, D. E. (2010). Excitability and synaptic communication within the oligodendrocyte lineage. J. Neurosci. 30, 3600-3611. doi: 10.1523/JNEUROSCI.6000-09.2010

Demerens, C., Stankoff, B., Logak, M., Anglade, P., Allinquant, B., Couraud, F., et al. (1996). Induction of myelination in the central nervous system by electrical activity. Proc. Natl. Acad. Sci. U.S.A. 93, 9887-9892. doi: 10.1073/pnas.93.18.9887

Doretto, S., Malerba, M., Ramos, M., Ikrar, T., Kinoshita, C., De Mei, C., et al. (2011). Oligodendrocytes as regulators of neuronal networks during early postnatal development. PLoS ONE 6:e19849. doi: 10.1371/journal.pone.0019849

Ehninger, D., Wang, L. P., Klempin, F., Römer, B., Kettenmann, H., and Kempermann, G. (2011). Enriched environment and physical activity reduce microglia and influence the fate of NG2 cells in the amygdala of adult mice. Cell Tissue Res. 345, 69-86. doi: 10.1007/s00441-011-1200-z

Etxeberria, A., Mangin, J. M., Aguirre, A., and Gallo V. (2010). Adult-born SVZ progenitors receive transient synapses during remyelination in corpus callosum. Nat. Neurosci. 13, 287-289. doi: 10.1038/nn.2500

Frühbeis, C., Fröhlich, D., Kuo, W. P., Amphornrat, J., Thilemann, S., Saab, A. S., et al. (2013). Neurotransmitter-triggered transfer of exosomes mediates oligodendrocyte-neuron communication. PLoS Biol. 11:e1001604. doi: 10.1371/journal.pbio. 1001604

Gallo, V., Mangin, J. M., Kukley, M., and Dietrich, D. (2008) Synapses on NG2-expressing progenitors in the brain: multiple functions? J. Physiol. 586, 3767-3781. doi: 10.1113/jphysiol.2008.158436
Galtrey, C. M., and Fawcett, J. W. (2007). The role of chondroitin sulfate proteoglycans in regeneration and plasticity in the central nervous system. Brain Res. Rev. 54, 1-18. doi: 10.1016/j.brainresrev.2006.09.006

Ge, W. P., Yang, X. J., Zhang, Z., Wang, H. K., Shen, W., Deng, Q. D., et al. (2006). Long-term potentiation of neuron-glia synapses mediated by $\mathrm{Ca} 2+$-permeable AMPA receptors. Science 312, 1533-1537. doi: 10.1126/science.1124669

Ge, W. P., Zhou, W., Luo, Q., Jan, L. Y., and Jan, Y. N. (2009). Dividing glial cells maintain differentiated properties including complex morphology and functional synapses. Proc. Natl. Acad. Sci. U.S.A. 106, 328-333. doi: 10.1073/pnas.0811353106

Gianola, S., Savio, T., Schwab, M. E., and Rossi, F. (2003). Cell-autonomous mechanisms and myelin-associated factors contribute to the development of Purkinje axon intracortical plexus in the rat cerebellum. J. Neurosci. 23, 4613-4624.

Haberlandt, C., Derouiche, A., Wyczynski, A., Haseleu, J., Pohle, J., Karram, K., et al. (2011). Gray matter NG2 cells display multiple Ca2+-signaling pathways and highly motile processes. PLoS ONE 6:e17575. doi: 10.1371/journal.pone. 0017575

Hamilton, N., Vayro, S., Wigley, R., and Butt, A. M. (2010). Axons and astrocytes release ATP and glutamate to evoke calcium signals in NG2-glia. Glia 58, 66-79. doi: 10.1002/glia.20902

Huang, W., Zhao, N., Bai, X., Karram, K., Trotter, J., Goebbels, S., et al. (2014) Novel NG2-CreERT2 knock-in mice demonstrate heterogeneous differentiation potential of NG2 glia during development. Glia 62, 896-913. doi: 10.1002/glia.22648

Hughes, E. G., Kang, S. H., Fukaya, M., and Bergles, D. E. (2013). Oligodendrocyte progenitors balance growth with self-repulsion to achieve homeostasis in the adult brain. Nat. Neurosci. 16, 668-676. doi: 10.1038/nn.3390

Kang, S. H., Fukaya, M., Yang, J. K., Rothstein, J. D., and Bergles, D. E. (2010). $\mathrm{NG} 2+\mathrm{CNS}$ glial progenitors remain committed to the oligodendrocyte lineage in postnatal life and following neurodegeneration. Neuron 68, 668-681. doi: 10.1016/j.neuron.2010.09.009

Káradóttir, R., Hamilton, N. B., Bakiri, Y., and Attwell, D. (2008). Spiking and nonspiking classes of oligodendrocyte precursor glia in CNS white matter. Nat. Neurosci. 11, 450-456. doi: 10.1038/nn2060

Kirby, B. B., Takada, N., Latimer, A. J., Shin, J., Carney, T. J., Kelsh, R. N., et al. (2006). In vivo time-lapse imaging shows dynamic oligodendrocyte progenitor behavior during zebrafish development. Nat. Neurosci. 9, 1506-1511. doi: $10.1038 / \mathrm{nn} 1803$

Kukley, M., Capetillo-Zarate, E., and Dietrich, D. (2007). Vesicular glutamate release from axons in white matter. Nat. Neurosci. 10, 311-320. doi: $10.1038 / \mathrm{nn} 1850$

Kukley, M., Kiladze, M., Tognatta, R., Hans, M., Swandulla, D., Schramm, J., et al. (2008). Glial cells are born with synapses. FASEB J. 22, 2957-2969. doi: 10.1096/fj.07-090985

Kukley, M., Nishiyama, A., and Dietrich, D. (2010). The fate of synaptic input to NG2 glial cells: neurons specifically downregulate transmitter release onto differentiating oligodendroglial cells. J. Neurosci. 30, 8320-8331. doi: 10.1523/JNEUROSCI.0854-10.2010

Lee, Y., Morrison, B. M., Li, Y., Lengacher, S., Farah, M. H., Hoffman, P. N., et al. (2012). Oligodendroglia metabolically support axons and contribute to neurodegeneration. Nature 487, 443-448. doi: 10.1038/nature11314

Levine, J. M., Reynolds, R., and Fawcett, J. W. (2001). The oligodendrocyte precursor cell in health and disease. Trends Neurosci. 24, 39-47. doi: 10.1016/S01662236(00)01691-X

Levison, S. W., Young, G. M., and Goldman, JE. (1999). Cycling cells in the adult rat neocortex preferentially generate oligodendroglia. J. Neurosci. Res. 57, 435-446.

Li, W., Tang, Y., Fan, Z., Meng, Y., Yang, G., Luo, J., et al. (2013). Autophagy is involved in oligodendroglial precursor-mediated clearance of amyloid peptide. Mol. Neurodegener. 8, 27. doi: 10.1186/1750-1326-8-27

Lin, S. C., and Bergles, D. E. (2004). Synaptic signaling between GABAergic interneurons and oligodendrocyte precursor cells in the hippocampus. Nat Neurosci. 7, 24-32. doi: 10.1038/nn1162

Lin, S. C., Huck, J. H., Roberts, J. D., Macklin, W. B., Somogyi, P., and Bergles D. E. (2005). Climbing fiber innervation of NG2-expressing glia in the mammalian cerebellum. Neuron 46, 773-785. doi: 10.1016/j.neuron.2005.04.025

Lu, B., Nagappan, G., Guan, X., Nathan, P. J., and Wren, P. (2013). BDNF-based synaptic repair as a disease-modifying strategy for neurodegenerative diseases. Nat. Rev. Neurosci. 14, 401-416. doi: 10.1038/nrn3505 
Lundgaard, I., Luzhynskaya, A., Stockley, J. H., Wang, Z., Evans, K. A., Swire, M., et al. (2013). Neuregulin and BDNF induce a switch to NMDA receptordependent myelination by oligodendrocytes. PLoS Biol. 11:e1001743. doi: 10.1371/journal.pbio. 1001743

Luyt, K., Slade, T. P., Dorward, J. J., Durant, C. F., Wu, Y., Shigemoto, R., et al. (2007). Developing oligodendrocytes express functional GABA(B) receptors that stimulate cell proliferation and migration. J. Neurochem. 100, 822-840. doi: 10.1111/j.1471-4159.2006.04255.x

Maglione, M., Tress, O., Haas, B., Karram, K., Trotter, J., Willecke, K., et al. (2010). Oligodendrocytes in mouse corpus callosum are coupled via gap junction channels formed by connexin 47 and connexin32. Glia 58, 1104-1117. doi: 10.1002/glia.20991

Maldonado, P. P., Vélez-Fort. M., Levavasseur, F., and Angulo, M. C. (2013). Oligodendrocyte precursor cells are accurate sensors of local $\mathrm{K}+$ in mature gray matter. J. Neurosci. 33, 2432-2442. doi: 10.1523/JNEUROSCI.1961-12.2013

Mangin, J. M., Kunze, A., Chittajallu, R., and Gallo, V. (2008). Satellite NG2 progenitor cells share common glutamatergic inputs with associated interneurons in the mouse dentate gyrus. J. Neurosci. 28, 7610-7623. doi: 10.1523/JNEUROSCI.1355-08.2008

Mangin, J. M., Li, P., Scafidi, J., and Gallo, V. (2012). Experience-dependent regulation of NG2 progenitors in the developing barrel cortex. Nat. Neurosci. 15, 1192-1194. doi: 10.1038/nn.3190

Martino, G., and Pluchino, S. (2006). The therapeutic potential of neural stem cells. Nat. Rev. Neurosci. 7, 395-406. doi: 10.1038/nrn1908

März, M., Schmidt, R., Rastegar, S., and Strähle, U. (2010) Expression of the transcription factor Olig2 in proliferating cells in the adult zebrafish telencephalon. Dev. Dyn. 239, 3336-3349. doi: 10.1002/dvdy.22455

Matthias, K., Kirchhoff, F., Seifert, G., Hüttmann, K., Matyash, M., Kettenmann, H., et al. (2003). Segregated expression of AMPA-type glutamate receptors and glutamate transporters defines distinct astrocyte populations in the mouse hippocampus. J. Neurosci. 23, 1750-1758.

Melanson-Drapeau, L., Beyko, S., Davé, S., Hebb, A. L., Franks, D. J., Sellitto, C., et al. (2003) Oligodendrocyte progenitor enrichment in the connexin32 nullmutant mouse. J. Neurosci. 23, 1759-1768.

Müller, J., Reyes-Haro, D., Pivneva, T., Nolte, C., Schaette, R., Lübke, J., et al. (2009). The principal neurons of the medial nucleus of the trapezoid body and NG2(+) glial cells receive coordinated excitatory synaptic input. J. Gen. Physiol.134, 115-127. doi: 10.1085/jgp.200910194

Munz, B., Tretter, Y. P., Hertel, M., Engelhardt, F., Alzheimer, C., and Werner, S. (2001). The roles of activins in repair processes of the skin and the brain. Mol. Cell. Endocrinol. 180, 169-177. doi: 10.1016/S0303-7207(01)00514-7

Nielsen, H. H., Ladeby, R., Drøjdahl, N., Peterson, A. C., and Finsen, B. (2006). Axonal degeneration stimulates the formation of NG2+ cells and oligodendrocytes in the mouse. Glia 54, 105-115. doi: 10.1002/glia.20357

Nishiyama, A., Watanabe, M., Yang, Z., and Bu J. (2002) Identity, distribution, and development of polydendrocytes: NG2-expressing glial cells. J. Neurocytol. 31, 437-455. doi: 10.1023/A:1025783412651

Nishiyama, A., Yu, M., Drazba, J. A., and Tuohy, V. K. (1997). Normal and reactive $\mathrm{NG} 2+$ glial cells are distinct from resting and activated microglia. J. Neurosci. Res.48, 299-312.

Ong, W. Y., and Levine, J. M. (1999) A light and electron microscopic study of NG2 chondroitin sulfate proteoglycan-positive oligodendrocyte precursor cells in the normal and kainate-lesioned rat hippocampus. Neuroscience 92, 83-95. doi: 10.1016/S0306-4522(98)00751-9

Passlick, S., Grauer, M., Schäfer, C., Jabs, R., Seifert, G., and Steinhäuser, C. (2013). Expression of the $\gamma 2$-subunit distinguishes synaptic and extrasynaptic GABA(A) receptors in NG2 cells of the hippocampus. J. Neurosci. 33, 12030-12040. doi: 10.1523/JNEUROSCI.5562-12.2013

Petrosyan, H. A., Hunanyan, A. S., Alessi, V., Schnell, L., Levine, J., and Arvanian, V. L. (2013). Neutralization of inhibitory molecule NG2 improves synaptic transmission, retrograde transport, and locomotor function after spinal cord injury in adult rats. J. Neurosci. 33, 4032-4043. doi: 10.1523/JNEUROSCI.470212.2013

Pfrieger, F. W., and Barres, B. A. (1997). Synaptic efficacy enhanced by glial cells in vitro. Science 277, 1684-1687. doi: 10.1126/science.277.5332.1684

Redwine, J. M., and Armstrong, R. C. (1998). In vivo proliferation of oligodendrocyte progenitors expressing PDGFalphaR during early remyelination. J. Neurobiol. 37, 413-428.
Rivers, L. E., Young, K. M., Rizzi, M., Jamen, F., Psachoulia, K., Wade, A., et al. (2008). PDGFRA/NG2 glia generate myelinating oligodendrocytes and piriform projection neurons in adult mice. Nat. Neurosci. 11, 1392-1401. doi: $10.1038 / \mathrm{nn} .2220$

Rosenberg, S. S., Kelland, E. E., Tokar, E., De la Torre, A. R., and Chan, J. R. (2008). The geometric and spatial constraints of the microenvironment induce oligodendrocyte differentiation. Proc. Natl. Acad. Sci. U.S.A. 105, 14662-14667. doi: 10.1073/pnas.0805640105

Shen, P. J., Larm, J. A., and Gundlach, A. L. (2003). Expression and plasticity of galanin systems in cortical neurons, oligodendrocyte progenitors and proliferative zones in normal brain and after spreading depression. Eur. J. Neurosci. 18, 1362-1376. doi: 10.1046/j.1460-9568.2003.02860.x

Sim, F. J., and Goldman, S. A. (2013). "Gene expression patterns of oligodendrocyte progenitor cells and oligodendroglia," in Neuroglia, eds E. Kettenmann and B. Ransom (Oxford: Oxford University Press), 358-373.

Sim, F. J., Lang, J. K., Waldau, B., Roy, N. S., Schwartz, T. E., Pilcher, W. H., et al. (2006). Complementary patterns of gene expression by human oligodendrocyte progenitors and their environment predict determinants of progenitor maintenance and differentiation. Ann. Neurol. 59, 763-779. doi: 10.1002/ana.20812

Sim, F. J., Windrem, M. S., and Goldman, S. A. (2009). Fate determination of adult human glial progenitor cells. Neuron Glia Biol. 5, 45-55. doi: 10.1017/S1740925X09990317

Simon, C., Götz, M., and Dimou, L. (2011). Progenitors in the adult cerebral cortex: cell cycle properties and regulation by physiological stimuli and injury. Glia 59, 869-881. doi: 10.1002/glia.21156

Stallcup, W. B. (2002) The NG2 proteoglycan: past insights and future prospects. J. Neurocytol. 31, 423-435. doi: 10.1023/A:1025731428581

Staugaitis, S. M., and Trapp, B. D. (2009) NG2-positive glia in the human central nervous system. Neuron Glia Biol. 5, 35-44. doi: 10.1017/S1740925X09990342

Stevens, B., Porta, S., Haak, L. L., Gallo, V., and Fields, R. D. (2002). Adenosine: a neuron-glial transmitter promoting myelination in the CNS in response to action potentials. Neuron 36, 855-868. doi: 10.1016/S0896-6273(02)01067-X

Sypecka, J., and Sarnowska, A. (2013). The neuroprotective effect exerted by oligodendroglial progenitors on ischemically impaired hippocampal cells. Mol. Neurobiol. 49, 685-701. doi: 10.1007/s12035-013-8549-9

Tamura, Y., Eguchi, A., Jin, G., Sami, M. M., and Kataoka, Y. (2012). Cortical spreading depression shifts cell fate determination of progenitor cells in the adult cortex. J. Cereb. Blood Flow Metab. 32, 1879-1887. doi: 10.1038/jcbfm.2012.98

Tanaka, Y., Tozuka, Y., Takata, T., Shimazu, N., Matsumura, N., Ohta, A., et al. (2009). Excitatory GABAergic activation of cortical dividing glial cells. Cereb. Cortex 19, 2181-2195. doi: 10.1093/cercor/bhn238

Tong, X. P., Li, X. Y., Zhou, B., Shen, W., Zhang, Z. J., Xu, T. L., et al. (2009). Ca(2+) signaling evoked by activation of $\mathrm{Na}(+)$ channels and $\mathrm{Na}(+) / \mathrm{Ca}(2+)$ exchangers is required for GABA-induced NG2 cell migration. J. Cell Biol. 186, 113-128. doi: $10.1083 /$ jcb.200811071

Tripathi, R. B., Rivers, L. E., Young, K. M., Jamen, F., and Richardson, W. D. (2010). NG2 glia generate new oligodendrocytes but few astrocytes in a murine experimental autoimmune encephalomyelitis model of demyelinating disease. J. Neurosci. 30, 16383-16390. doi: 10.1523/JNEUROSCI.3411-10.2010

Vélez-Fort, M., Maldonado, P. P., Butt, A. M., Audinat, E., and Angulo, M. C. (2010). Postnatal switch from synaptic to extrasynaptic transmission between interneurons and NG2 cells. J. Neurosci. 30, 6921-6929. doi: 10.1523/JNEUROSCI.0238-10.2010

Wake, H., Lee, P. R., and Fields, R. D. (2011). Control of local protein synthesis and initial events in myelination by action potentials. Science 333, 1647-1651. doi: $10.1126 /$ science. 1206998

Wallraff, A., Odermatt, B., Willecke, K., and Steinhäuser, C. (2004) Distinct types of astroglial cells in the hippocampus differ in gap junction coupling. Glia 48, 36-43. doi: 10.1002/glia.20040

Wang, S., and Young, K. M. (2013). White matter plasticity in adulthood. Neuroscience. doi: 10.1016/j.neuroscience.2013.10.018. [Epub ahead of print].

Wigley, R., and Butt, A. M. (2009) Integration of NG2-glia (synantocytes) into the neuroglial network. Neuron Glia Biol. 5, 21-28. doi: 10.1017/S1740925X09990329

Wilkins, A., Chandran, S., and Compston, A. (2001). A role for oligodendrocytederived IGF-1 in trophic support of cortical neurons. Glia 36, 48-57. doi: 10.1002/glia.1094 
Yoshida, Y., Sakakima, H., Matsuda, F., and Ikutomo, M. (2014). Midkine in repair of the injured nervous system. Br. J. Pharmacol. 171, 924-930. doi: 10.1111/bph.12497

Young, K. M., Psachoulia, K., Tripathi, R. B., Dunn, S. J., Cossell, L., Attwell, D., et al. (2013). Oligodendrocyte dynamics in the healthy adult CNS: evidence for myelin remodeling. Neuron 77, 873-885. doi: 10.1016/j.neuron.2013.01.006

Zatorre, R. J., Fields, R. D., and Johansen-Berg, H. (2012). Plasticity in gray and white: neuroimaging changes in brain structure during learning. Nat. Neurosci. 15, 528-536. doi: 10.1038/nn.3045

Zawadzka, M., Rivers, L. E., Fancy, S. P., Zhao, C., Tripathi, R., Jamen., F., et al. (2010). CNS-resident glial progenitor/stem cells produce Schwann cells as well as oligodendrocytes during repair of CNS demyelination. Cell Stem Cell 6, 578-590. doi: 10.1016/j.stem.2010.04.002

Zhang, Y. W., Denham, J., and Thies, R. S. (2006). Oligodendrocyte progenitor cells derived from human embryonic stem cells express neurotrophic factors. Stem Cells Dev. 15, 943-952. doi: 10.1089/scd.2006.15.943

Zhu, X., Bergles, D. E., and Nishiyama, A. (2008a). NG2 cells generate both oligodendrocytes and gray matter astrocytes. Development 135, 145-157. doi: 10.1242/dev.004895

Zhu, X., Hill, R. A., Dietrich, D., Komitova, M., Suzuki, R., and Nishiyama, A. (2011). Age-dependent fate and lineage restriction of single NG2 cells. Development 138, 745-753. doi: 10.1242/dev.047951
Zhu, X., Hill, R. A., and Nishiyama, A. (2008b). NG2 cells generate oligodendrocytes and gray matter astrocytes in the spinal cord. Neuron Glia Biol. 4, 19-26. doi: 10.1017/S1740925X09000015

Ziskin, J. L., Nishiyama, A., Rubio, M., Fukaya, M., and Bergles, D. E. (2007). Vesicular release of glutamate from unmyelinated axons in white matter. Nat. Neurosci. 10, 321-330. doi: 10.1042/AN20110001

Conflict of Interest Statement: The authors declare that the research was conducted in the absence of any commercial or financial relationships that could be construed as a potential conflict of interest.

Received: 21 March 2014; accepted: 06 May 2014; published online: 23 May 2014. Citation: Boda E and Buffo A (2014) Beyond cell replacement: unresolved roles of NG2-expressing progenitors. Front. Neurosci. 8:122. doi: 10.3389/fnins.2014.00122

This article was submitted to Neurogenesis, a section of the journal Frontiers in Neuroscience.

Copyright (C) 2014 Boda and Buffo. This is an open-access article distributed under the terms of the Creative Commons Attribution License (CC BY). The use, distribution or reproduction in other forums is permitted, provided the original author(s) or licensor are credited and that the original publication in this journal is cited, in accordance with accepted academic practice. No use, distribution or reproduction is permitted which does not comply with these terms. 